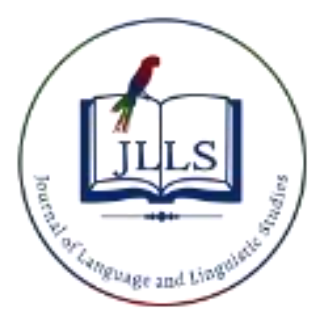

Available online at www.jlls.org

JOURNAL OF LANGUAGE AND LINGUISTIC STUDIES

ISSN: 1305-578X

Journal of Language and Linguistic Studies, 16(2), 537-551; 2020

\title{
Bronfenbrenner's theory and teaching intervention: The case of student with intellectual disability
}

\author{
Nikolaos Panopoulos $^{\mathrm{a}} 1$ (D), Maria Drossinou-Korea ${ }^{\mathrm{b}}$ \\ ${ }^{a}$ University of Peloponnese, Kalamata, Greece \\ ${ }^{b}$ University of Peloponnese, Kalamata, Greece
}

\section{APA Citation:}

Panopoulos N. \& Drossinou-Korea M. (2020). Bronfenbrenner's theory and teaching intervention: The case of student with intellectual disability. Journal of Language and Linguistic Studies, 16(2), 537-551.

Submission Date:14/09/2019

Acceptance Date:10/01/2020

\begin{abstract}
The aim of this study is to highlight the importance of teaching interventions in accordance with Bronfenbrener's Ecosystem Theory. The research questions address, how reading skills are taught in the microsystem of school through a Targeted, Individual, Structured, Integrated Program for Students with Special Educational Needs (TISIPfSENs) and how meso- exo-, macro- and chrono-system shape the structure of the intervention to enhancing reading skills. The methodology refers to a case study of a student with intellectual disability (ID) in Greece. The results indicate that the student with ID has enhanced his reading skills. The conclusions highlight the factors that influence and shape the educational intervention of reading skills in students with ID in accordance with Bronfenbrener's Ecosystem Theory.
\end{abstract}

(C) 2020 JLLS and the Authors - Published by JLLS.

Keywords: Intellectual disability; reading skills; TISIPfSENs; Bronfenbrenner's

\section{Introduction}

Students with intellectual disability have difficulty to be included in the school community (Drossinou - Korea, Matousi, Panopoulos, \& Paraskevopoulou, 2016). One of the main problems they face is their participation in the general education curriculum, as they go to secondary education. In the present study we investigate the special teaching methodology that contributes to the active participation of students in the learning process and the factors that may influence the special teaching methodology of their language skills based on Bronfenbrener's theory (Anderson, Boyle \& Deppeler, 2014).

\subsection{Literature review}

\subsubsection{Intellectual disability}

Intellectual disability is defined by the sixth edition of the American Psychiatric Association's Diagnostic and Statistical Manual of Mental Disorders as deficits in the intellectual ability and the functions of adaptive and behavioral skills during the developmental period of his life (American

\footnotetext{
${ }^{1}$ Corresponding author. Tel.: +0-000-000-0000

E-mail address: nikospano@windowslive.com
} 
Psychiatric Association, 2013, p. 33). Students with intellectual disability are forming a heterogeneous group depending on the percentage of the above deficits (mild, moderate, severe and very severe intellectual disability) (Bouck \& Bone, 2018, pp. 55,56). According to Gargiulo and Bouck (2017) and their scientific work on teaching interventions for students with intellectual disability, this particular group of students has deficiencies in areas that impede the learning process, such as concentration and short-term attention, short-term learning and working memory, lack of motivation, ability to generalize skills, language development, behavioral skills, and academic performance, such as reading comprehension (pp. 40-44). Or van Wingerden, Segers, van Balkom, and Verhoeven (2017) in their article on linguistic and cognitive factors affecting reading comprehension of students with intellectual disability, compared comprehension skills, word decoding, auditory comprehension, as well as factors contributing to their acquirement of vocabulary, grammar, short-term memory, rapid automatic naming, and working memory, among students with intellectual disability and their normally developing peers. They concluded that the skills of students with intellectual disability were lower than those of their peers. Similarly, a research article by Channell, Loveall and Conners (2013) in a scientific article on adolescents' abilities and weaknesses in reading skills concluded that these students had significant deficits in phonological awareness and perception skills and word coding and decoding. Still, according to Afacan, Wilkerson, and Ruppar (2018), in their article on reading interventions for students with intellectual disability, they argue that these students have more language skills deficits than their peers. Four out of five students with intellectual disability do not reach satisfactory levels of reading ability, mainly in decoding and word coding, comprehension and writing skills. According to themselves, as language skills contribute to these students' further achievements, such as their successful schooling and active community involvement, it is necessary to find differentiated language teaching practices such as comprehension, vocabulary, reading skills, decoding and coding words, as well as writing. Also, the same researchers emphasize the need for differentiated teaching interventions to be implemented in general school classrooms, as these students are likely to be more involved in the lessons and achieve age-appropriate teaching goals. The same researchers point out that teaching language skill to students with intellectual disability has not been sufficiently explored in secondary education, thus requiring more research to investigate the issue in the integrated school contexts proposing innovative educational strategies. Over the past two decades, researchers have taken the view that students with intellectual disabilities are able to cope not only with individual language activities, such as visual word discrimination, but also with decoding and coding skills for reading \& comprehension skills. (Dessemontet \& de Chambrier, 2015). Finally, or Allor, Mathes, Roberts, Jones, Cheatham, and Chamblin (2010) in their article on the implementation and evaluation of an integrated teaching intervention to support reading skills in students with intellectual disability report that these students can be improved reading comprehension skills. Specifically, the curriculum they implemented included activities such as identifying title, words, and sentences in a text, word decoding skills, students' rhythms, hand-letter and sound matching activities, text comprehension strategies, and word reflection and comprehension activities. They also recommended further research to come up with new diversified educational strategies for learning reading comprehension skills in this particular student group.

\subsubsection{Targeted, Individual, Structured, Integrated Program for Students with Special Educational Needs (TISIPfSENS)}

The Targeted, Individual, Structured, Integrated Special Education and Training Program (TISIPfSENs) is a pedagogical tool for the special education and training teacher to structure, implement and evaluate his/her curriculum in the classroom. According to Drossinou-Korea (2017), TISIPfSENs is utilized by students with special educational needs (SEN), such as those with intellectual disability, for their educational and pedagogical care with appropriate teaching management, alternative assessment and differentiated teaching (pp. 311-312). 
This pedagogical tool is governed by a number of pedagogical and teaching principles derived from the original letters of the words-concepts that define it (TISIPfSENs) (Drossinou-Korea, 2017, pp. 338347) (Figure 1): (a) educational program needs to be Targeted. The teacher constructs functional and realistic teaching goals for each student, which they break down into teaching steps according to the task analysis method. (b) The curriculum needs to be individualized to be tailored to the students' abilities and weaknesses. The personalization of the program involves modifying the school environment, strategies and teaching methods. (c) The program needs to be Structured. Through this pedagogical tool, the teacher constructs his / her educational task in the following phases:

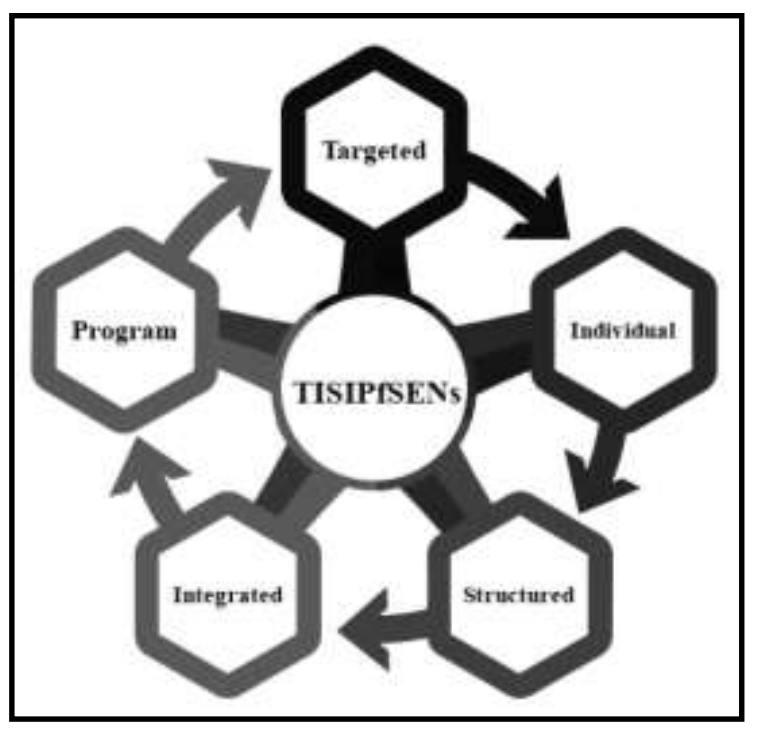

Figure 1. Pedagogical tool "TISIPfSENs"

(1) In the first phase, the teacher collects the student's personal, school and family history in collaboration with the school staff, extracurricular staff who are therapeutically involved and their teachers with the family environment. (2) In the second phase, the teacher performs the initial informal pedagogical assessment of the students through certain checklists of basic skills (CBSs) in order to assess their abilities and deficits according to their levels of readiness, their specific educational needs, such as in the Special Education Curriculum Framework (SECF), of their general learning difficulties according to the School Curriculum and based on their specific learning difficulties. (3) In the third phase, the teacher builds the syllabus plan setting out the teaching objectives, pedagogical materials and the learning environment. (4) In the fourth phase, the teaching is carried out using direct teaching by applying the differentiated teaching intervention. (5) In the fifth phase, the teacher performs the final informal pedagogical assessment based on the CBSs to decide on the student's transition to the next school classroom (Figure 2). (d) The curriculum needs to be Integrated. It is used in the mainstream school to promote school and social inclusion of students with SEN. (e) The pedagogical tool contributes to the development of a weekly and daily program, which is an educational guide with learning objectives and teaching objectives, activities, methods, materials and assessment tools. The program is used in the field of special education and training, as its preparation requires interdisciplinary collaboration between special education staff, special education staff and general education staff. 


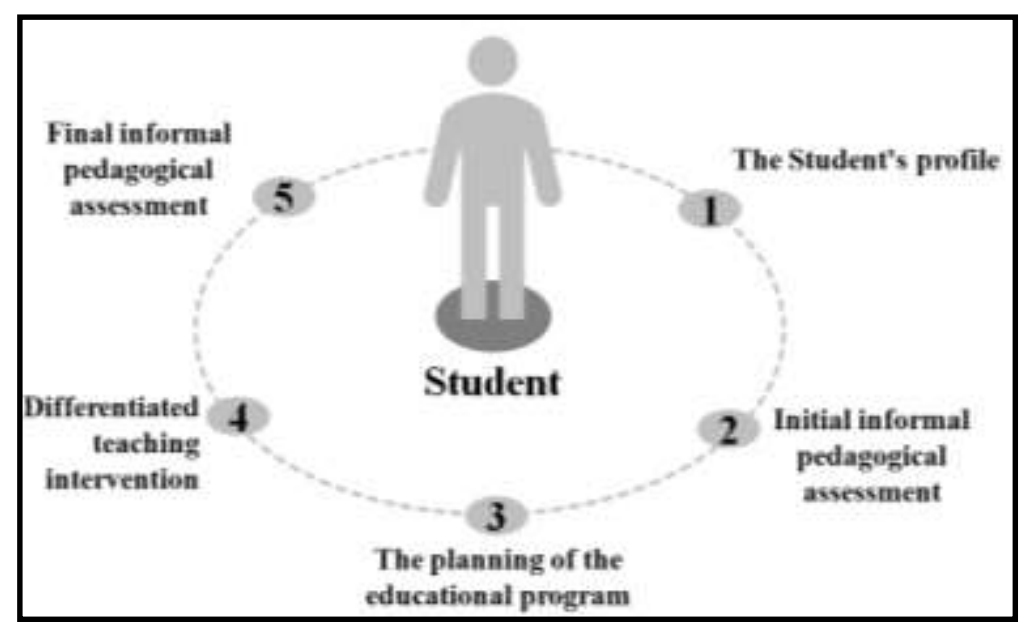

Figure 2. Phases of the TISIPfSENs

\subsubsection{Bronfenbrenner's theory}

Urie Bronfenbrenner introduced the ecosystem theory in order to understand human development by focusing heavily on the contribution of the environment and the effects it has on this development process (Bronfenbrenner \& Morris, 2006, pp. 793-828). The central point of his theory relates to the interactions created between the developing and active human organism and the nearer and wider social context that surrounds it and influences it directly and indirectly (Petrogiannis, 2003, p. 11). O1 Rosa and Tudge (2013) argue that Urie Bronfenbrenner's theory is divided into three successive phases based on his published scientific work. In the first phase, Bronfenbrenner called his emerging theoretical approach an ecological model of human development. The ecology of human development is defined as the exploration of the adaptation of the human body to the ever-changing environment, as this developmental process is shaped by the relationships it has with the surrounding environments in which it plays a leading role and the role it shapes in the wider social context (Petrogiannis, 2003, p. 60). The first version of this theoretical approach involves the topological layout of the ecological environment, which is governed by four systems, the microsystem, the mesosystem, the extrosystem, and the macrosystem (Rosa \& Tudge, 2013). At the center of these systems is the individual. Each of these levels is embedded in its immediate next and is influenced by their distance to the central unit, the individual (Petrogiannis, 2003, pp. 81-84). The microsystem comprises of the daily environments in which the person transits and makes reciprocal face-to-face contacts (Hayes, O'Toole, \& Halpenny, 2017, p. 15). The mesosystem includes the connections between two or more microsystems in which the developing individual is actively involved (Rosa \& Tudge, 2013). The exosystem as a third cycle of the ecological model is governed by environments or contexts in which the individual is not actively involved but is indirectly affected (Petrogiannis, 2003, pp. 143-147). The macrosystem is the fourth and broadest level of the individual encompassing traditions, political strategies, social and political values, and cultural beliefs that influence the functioning of other systems and thus the central unit, the individual (Hayes, O'Toole, \& Halpenny, 2017, pp. 16-17). ). In the second phase of this theoretical approach, the ecological model was renamed to a bio-ecological model, as it was understood that the human development depends not only on the effects of the environment but also on the characteristics of the individual in dealing with the environment (Rosa \& Tudge, 2013). ). The individual is not a passive recipient of the influences he or she receives from social contexts but plays an active role in their development (Bronfenbrenner \& Morris, 2006, pp. 793-828). It is governed by characteristics such as motivations and goals, levels of activity and temperament, but also by external appearance characteristics that influence the goals and expectations of others (Petrogiannis, 2003, p. 77). In addition to the four systems, Bronfenbrenner also introduced another system, the chronosystem, which refers to 
the lifelong development of the individual, to the changes observed in the individual himself, as well as to the effect that changes have on his evolution over the time in the environments in which he lives (Petrogiannis, 2003, pp. 189-206). In the third and final phase of the theory, Bronfenbrenner further clarified the importance of the combinatorial process-person-context-time model. Human development occurs through constant, regular, and continuous interactions (proximal processes) involving the transfer of energy between the developing active individual and other individuals, objects, and symbols of their immediate environment (Rosa \& Tudge, 2013). Accordingly, human development is defined as the set of processes through which the characteristics and properties of the active and evolving biopsychological human organism and its environment interact to evolve the individual during his or her life (Petrogiannis, 2003, p. 73).

One of the most important microsystems of one's life is that of school (Figure 3). The school environment, the learning process, and the relationships students develop with SEN with their peers and teachers contribute to their social, cognitive and academic development (Anderson, Boyle, \& Deppeler, 2014; Hayes, O'Toole, \& Halpenny, 2017). According to Petrogiannis (2003) the school is governed by social and physical elements, each of which contributes to the development of each student. The social elements of the microsystem include students, teachers, the principal, and their relationships, while the physical elements include the school building, the classrooms, the courtyard, the curriculum, and the teaching methods (Petrogiannis, 2003, pp. 112-113). According to the ecosystem model for the education of students with SEN within the school context, their characteristics, such as gender, age, type of special educational needs, such as mental disability, as well as their educational abilities or weaknesses play an important role in their academic and social background and environment (Ruppar, Allcock, \& Gonsier-Gerdin, 2017). Moving into the microsystem of school the student's learning path with the SEN is influenced by those he or she is in direct contact with, such as teachers whose low expectations of integrating students with intellectual disabilities into secondary school most of the time become an inhibiting factor to their academic progress (Molfenter \& Hanley-Maxwell, 2017). Still, relationships between the student and peers can greatly influence his or her social and learning behavior (Schwab, Gebhardt, Krammer, \& Gasteiger-Klicpera, 2015). In the mesosystem, interconnections occur between the school and other microsystems, such as the family, therapeutic centers, or diagnostic centers, which influence the student's learning path with SEN (Anderson, Boyle, \& Deppeler, 2014). In Greece, Diagnostic Centers are called Educational and Counseling Support Centers (ECSC), where students' performance is assessed and a diagnosis of special educational needs, such as intellectual disability, is provided. The exosystem includes the experiences, values, and teacher education that make up the school culture, and therefore their decisions and choices influence students with SEN, such as those with intellectual disability in inclusive school environments (Gajewski, 2017; Anderson, Boyle, \& Deppeler, 2014). The macrosystem includes laws regarding educational policies that are indirectly affecting the school life of a mentally disabled student (Ainscow, Dyson, \& Weiner, 2013). In Greece, since 2008 under Law 3699, an accession policy has been implemented, according to which students with intellectual disability can attend general schools with the presence of a second teacher in general classes, who is specialized in the field of special education and education (Law 3699, 2008). Further, factors that indirectly influence a student's learning and social course with SEN are the curricula of general education and special education and training (Anderson, Boyle, \& Deppeler, 2014). Finally, the chronosystem includes the student's educational transitions from one classroom to another or from primary to secondary (Hayes, O'Toole, \& Halpenny, 2017, p. 17). Another dimension of the chronosystem is the student's attendance during the school year, which is assessed by continuous informal pedagogical assessment, in order to modify the curriculum according to changes observed in the student with SEN, such as those with intellectual disability (Drossinou-Korea, 2017, p. 397). 


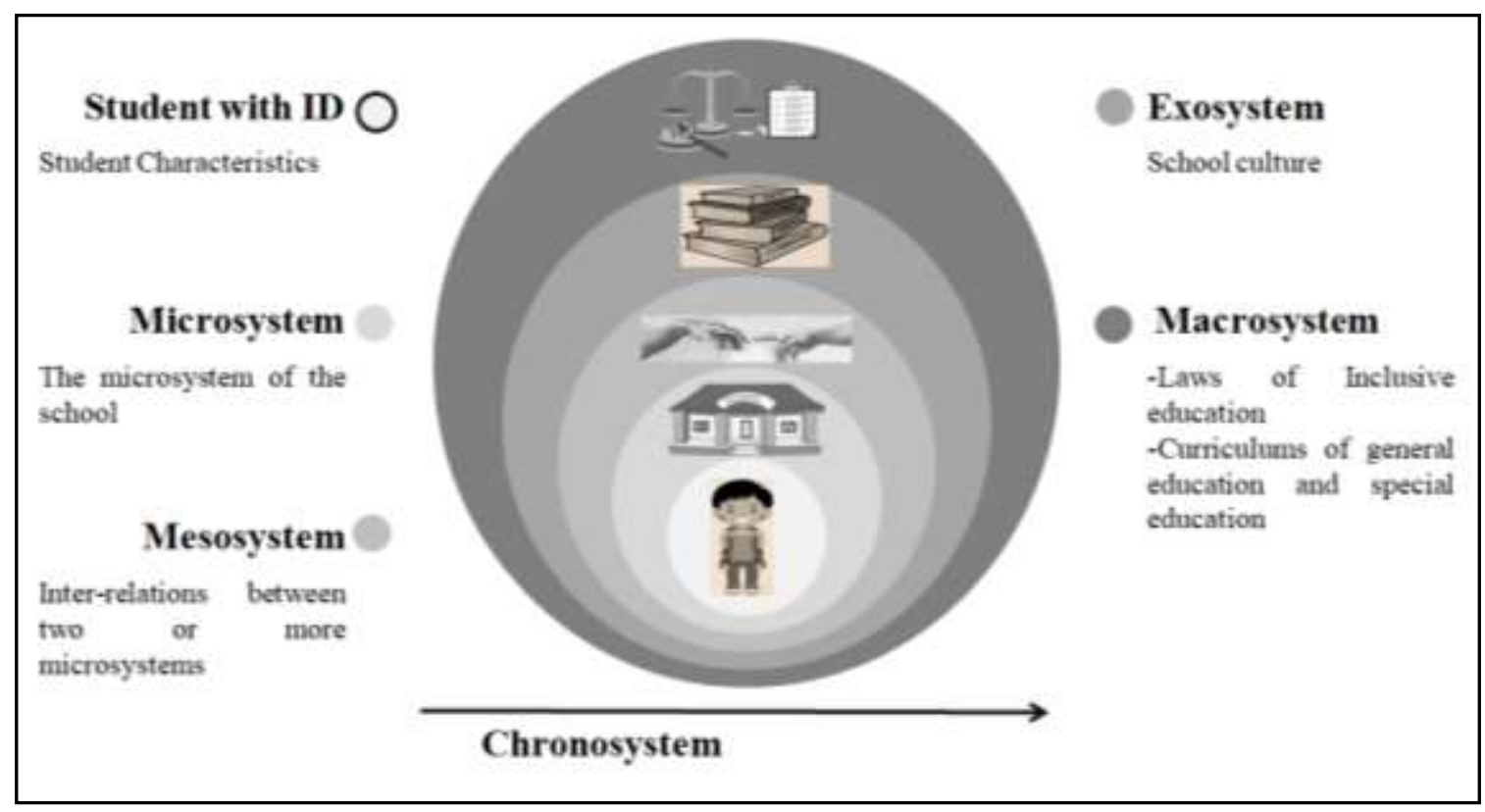

Figure 3. Ecological systems model in education for students with special educational needs

\subsection{Research questions}

The purpose of the present study through the case study of a student with intellectual disabilities is to implement and evaluate the pedagogical tool, TISIPfSENs, in the secondary school microsystem. According to Ruppar, Allcock, and Gonsier-Gerdin (2017), ecological systems theory is useful in order to explain how educational and social structures influence students' school integration with SEN. In their article on the factors that influence the inclusion of students with significant disabilities into mainstream schooling, it is argued that ecological systems theory is a perspective to provide recommendations for appropriate educational and teaching planning. Additionally, Okyere, Aldersey, and Lysaght (2019) while examining the educational inclusion of students with cognitive and developmental disabilities based on Bronfenbrenner's bioecological theory, have found that the characteristics of students with SEN, the contact with students' parents (minors), the educational resources, such as teaching materials and the educational services that support and advise teachers (mesosystem), influence the teaching interaction in the classroom and thus their school integration.

Consequently, the research questions that arise are: (a) How does TISIPfSENs support the reading comprehension skills of students with intellectual disabilities in secondary school? (b) How the systems (mesosystem, extrosystem, macrosystem and chronosystem) of the Bronfenbrenner's bioecological model of theory affect reading comprehension interventions in a student with intellectual disabilities?

\section{Method}

This study utilized qualitative research in the context of action research in the secondary school. Specifically we examined a case study of a student with a mental disability for 6 months. According to Avramidis and Kalyva (2006), case studies are appropriate for researching a contemporary phenomenon in a real context, such as the school environment (p. 302).

\subsection{Sample / Participants}

The student with intellectual disability was 16 years old and attended the first grade of High School in Peloponnese, Greece. His class consisted of 23 students, one general education teacher and one special 
education and training teacher. The teacher of special education supported the student in literary lessons, such as History, in the duration of 10 lessons per week.

\subsection{Instrument $(s)$}

To collect the qualitative data, we conducted an Informal Pedagogical Assessment (IPA) with some CBS (Andrews, 2008), such as CBS of special education needs, as defined by the Greek SECF and the CBS of general learning disabilities defined in accordance with the curriculum of the class in which the student with intellectual disability was studying (Drossinou-Korea, 2017, pp. 396-432). The IPA extends to three different time periods: initial, intermediate and final. The initial informal IPA is performed prior to the implementation of the syllabus. The intermediate IPA is done during the syllabus, while the final IPA shall take place after the end of the educational program. The CBS of special education needs, as defined by SECF, were depicted in an excel table, which consisted of a horizontal line listing the behaviors observed, such as oral skills, psychomotor and cognitive abilities, academic as well as social skills, creative skills and pre-vocational skills. The CBS of general learning difficulties for literary subjects, such as history, contains language skills in reading, writing and speech production, neurodevelopmental areas of oral speech, psychomotor, cognitive and emotional abilities and also skills of positive, negative and offensive behavior. Each of the above CBSs consists of a vertical column. It lists the semesters of formal and compulsory study on an ascending scale from the 1st semester (kindergarten, 1st semester) to the 26th semester (third grade of high school, 2nd semester), where secondary education is completed in Greece. A solid line crosses the board horizontally symbolizing the student's class and semester. The researcher in these tables is asked to assess the student's level of competence on a scale of semesters of formal and compulsory education, in order to identify any discrepancies on the baseline and to define the teaching priorities. When this procedure is completed, a dotted line is created that shows the student's highest and lowest deviation from the baseline. The researcher-teacher of special education is asked to create three dashed lines that record the student's performance during the initial, intermediate, and final IPA (Drossinou-Korea, 2017, p. 397).

\subsection{Data collection procedures}

The procedure of the research followed the five phases of the TISIPfSENs. The research was carried out by a second-grade teacher specializing in special education and postgraduate education in the implementation of the TISIPfSENs pedagogical tool in secondary schools. She also had three years of teaching language skills for students with intellectual disabilities in general schools. In the first phase of TISIPfSENs, the researcher collected the student's personal, school, and family history. Individual history was taken into account by the Diagnostic and Support Center for Diagnosis and Support, according to which the student had moderate intellectual disability. For the school's history background the researcher took into account the pedagogical reports of teachers of previous school years that taught the student, as well as the opinions of general education teachers that were teaching in the classroom. According to them, most of the time the student's oral speech was correctly delivered. However, he could not always engage in a dialogue, as he usually referred only to issues that concerned his interests. Usually while being in classroom he would not talk and would not focus on the teacher. The reading ability of the student was characterized as moderate, as he was reading at a fast pace, pausing and without discretion. He was unable to comprehend the text which had mere grammatical and editorial structure and found it difficult to find ways of processing deeper meanings in the information given to him. The family history researcher collaborated with the student's parents and took note of their request: that the student might be interested in literary lessons, such as history. In the second phase, the researcher carried out the initial informal pedagogical assessment according to the CBSs. According to the CBS for special educational needs, reading comprehension was defined as a teaching priority, as the student's skills were 
enrolled in the 14th semester (fifth grade of Elementary, second semester), while the student was enrolled in the 21st semester (first grade of high school, first semester) (figure 4). According to the CBS of general learning based on the literacy curriculum, the understanding of texts in school literacy courses was defined as a teaching priority, as the student's abilities were assessed in the 14th semester (fifth grade of Elementary, fifth semester). That is, his abilities were assessed as being 7 semesters below the student's baseline (first grade of high school, first semester). The third phase defined the school lesson, the story, where the didactic intervention was made, and the general objective which was formulated by the teacher of the general education, was for the student to be able "to read and understand 10 sentences of a text (Verdana font, normal style and size 14) with 20 visual conceptual facilitators applying comprehension strategies by designing logical reasoning tables". This objective was taught in 10 teaching steps, using the task analysis method. In the fourth phase, didactic intervention was implemented through direct teaching in the general classroom. The researcher instructed the student to complete the differentiated pedagogical material included in a properly structured dossier. During the fourth phase, the teacher of general education and the teacher of special education conducted the interim informal pedagogical assessment according to the CBSs. In the fifth phase of TISIPfSENs, the researcher performed the final informal pedagogical evaluation of the student according to the CBSs and then recorded the qualitative data.

\section{Results}

According to the CBS of special education needs, as defined by SECF, the student was able to improve his or her comprehension skills by 2 semesters (first grade of middle school, first semester) compared to the initial informal pedagogical assessment. Furthermore, it improved by one semester of study in reading (16th semester), oral (18th semester) and social behavior (19th semester) skills (figure 4).

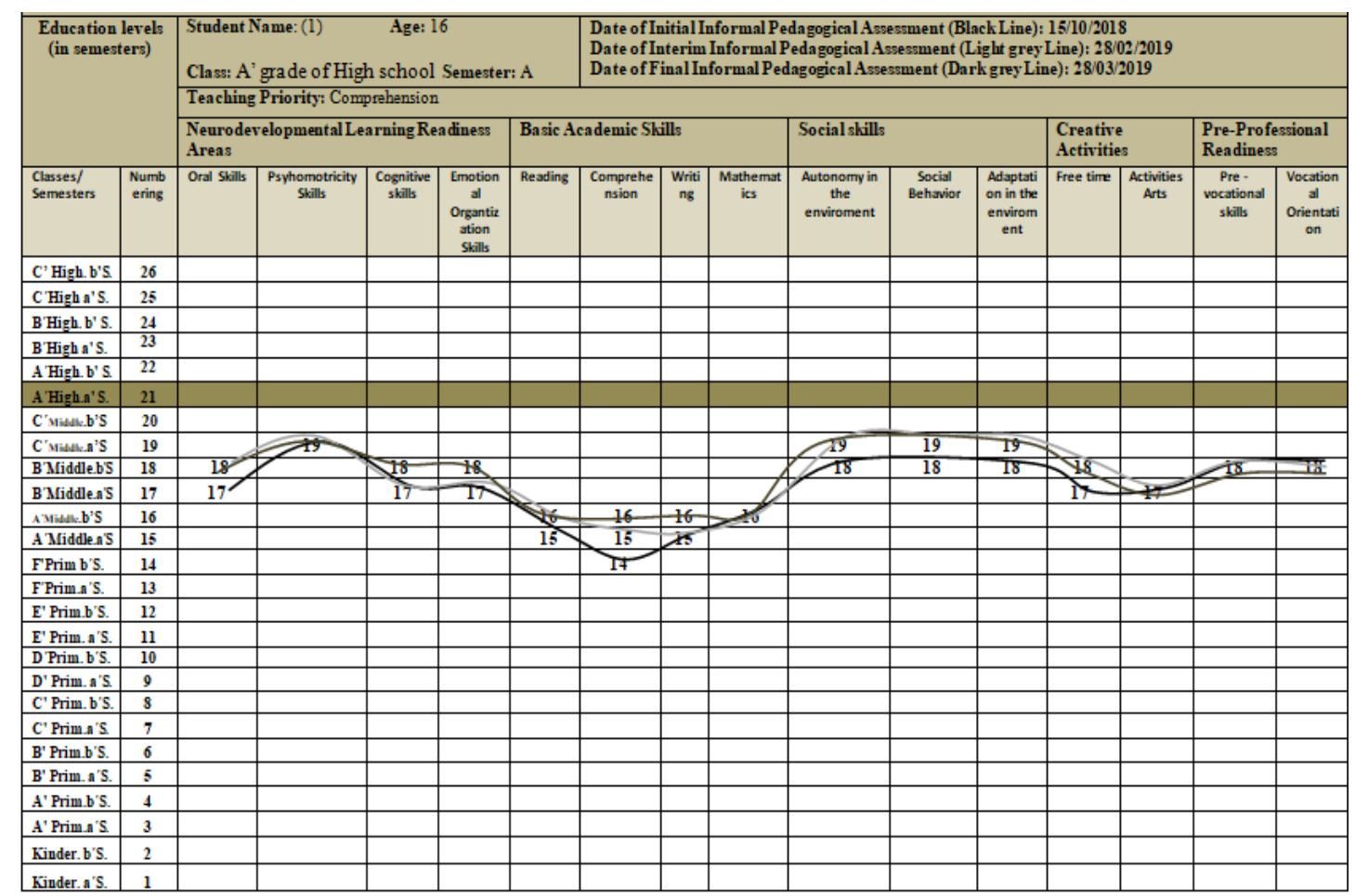

Figure 4. Checklists of basic skills of Framework Curriculum for Special Education 
With regard to CBS of general learning difficulties, as defined by the Curriculum for the history lesson taught, the student improved in comprehension skills as his performance was recorded in the 16th semester (first class of middle school, first semester in figure 5).

\begin{tabular}{|c|c|c|c|c|c|c|c|c|c|c|c|c|c|c|}
\hline \multirow{2}{*}{\multicolumn{2}{|c|}{$\begin{array}{l}\text { Education } \\
\text { levels (in } \\
\text { semesters) }\end{array}$}} & \multicolumn{5}{|c|}{$\begin{array}{l}\text { Student's Name: (1) Age: } 16 \\
\text { Class! A' grade of Highschool Semesteri A' }\end{array}$} & \multicolumn{8}{|c|}{ 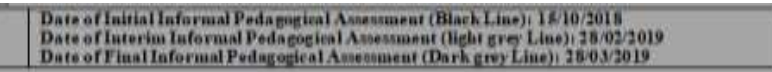 } \\
\hline & & \multicolumn{13}{|c|}{ Teaching priorityt Comprehension } \\
\hline \multirow{2}{*}{$\begin{array}{c}\text { Clanes } \\
\text { Semeste } \\
\text { ns }\end{array}$} & \multirow{2}{*}{$\begin{array}{c}\begin{array}{c}N a \\
m b \\
w i \\
w i\end{array} \\
\text { ait }\end{array}$} & \multicolumn{3}{|c|}{ 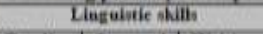 } & \multicolumn{4}{|c|}{ Skilis for Learaine Keadiaen } & \multicolumn{3}{|c|}{ Mbathematical ocili } & \multicolumn{3}{|c|}{ Betarioral Shallh } \\
\hline & & Readiag & $\begin{array}{c}\text { Compreb } \\
\text { easion }\end{array}$ & Writieg & $\begin{array}{l}\text { Oral } \\
\text { shili }\end{array}$ & $\begin{array}{l}\text { Pyghomeor } \\
\text { ifity shilth }\end{array}$ & \begin{tabular}{c|} 
Cogairive \\
silt
\end{tabular} & $\begin{array}{c}\text { Emotional } \\
\text { oreaniratio } \\
\text { a shill. }\end{array}$ & $\begin{array}{c}\text { Number } \\
\mathrm{m}\end{array}$ & 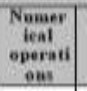 & $\begin{array}{c}\text { Numerieal } \\
\text { problems }\end{array}$ & $\begin{array}{l}\text { Positive } \\
\text { belaviers }\end{array}$ & \begin{tabular}{|l|} 
Netarive \\
belaviors
\end{tabular} & $\begin{array}{l}\text { Delinque } \\
\text { ay }\end{array}$ \\
\hline C'migh b's & 26 & & & & & & & & & & & & & \\
\hline CHighes.s. & 26 & & & & & & & & & & & & & \\
\hline 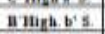 & 24 & & & & & & & & & & & & & \\
\hline BHighe's. & 23 & & & & & & & & & & & & & \\
\hline Allintís & 22 & & & & & & & & & & & & & \\
\hline A minis: & 21 & & & & & & & & & & & & & \\
\hline$C^{\prime M}$ Mind's & 20 & & & & & & & & & & & & & \\
\hline C Matis is & 19 & & & & & 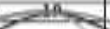 & & & & & & $19-1$ & & \\
\hline Bxhidatebs & 18 & & & & & & $>18$ & 18 & & & & $18-1$ & 18 & \\
\hline DMMidtleas & 17 & & & & & & it & 17 & $\mathrm{~W}$ & Whes & & 12 & 12 & \\
\hline Amanb's & 16 & 16 & 16 & - 16 & & & & & & & He & & & \\
\hline A Miditles 8 & 16 & 10. & 16 & 10 & & & & & & & & & & \\
\hline reriabs & 14 & & 14 & It & & & & & & & & & & \\
\hline rPhimas. & 13 & & & & & & & & & & & & & \\
\hline K Frimbs & 12 & & & & & & & & & & & & & \\
\hline F Frim. as & 11 & & & & & & & & & & & & & \\
\hline D Prim b's. & 10 & & & & & & & & & & & & & \\
\hline D' Fria.n $\&$ & 9 & & & & & & & & & & & & & \\
\hline C'Prim. bs & 8 & & & & & & & & & & & & & \\
\hline C'Primens & 7 & & & & & & & & & & & & & \\
\hline D. Priabs: & 6 & & & & & & & & & & & & & \\
\hline B' Prim. os & 6 & & & & & & & & & & & & & \\
\hline A' Primbs 8 & 4 & & & & & & & & & & & & & \\
\hline A' Primas 8 & 3 & & & & & & & & & & & & & \\
\hline Kinder. b'5. & 2 & & & & & & & & & & & & & \\
\hline & 1 & & & & & & & & & & & & & \\
\hline
\end{tabular}

Figure 5. Checklists of basic skills for general learning difficulties

Specifically, the student understood differentiated texts that came from the History textbook, as they consisted of small sentences with simple vocabulary, active writing and definitive adaptation and visual conceptual facilitators to understand historical concepts or ancient cultures (figure 6).

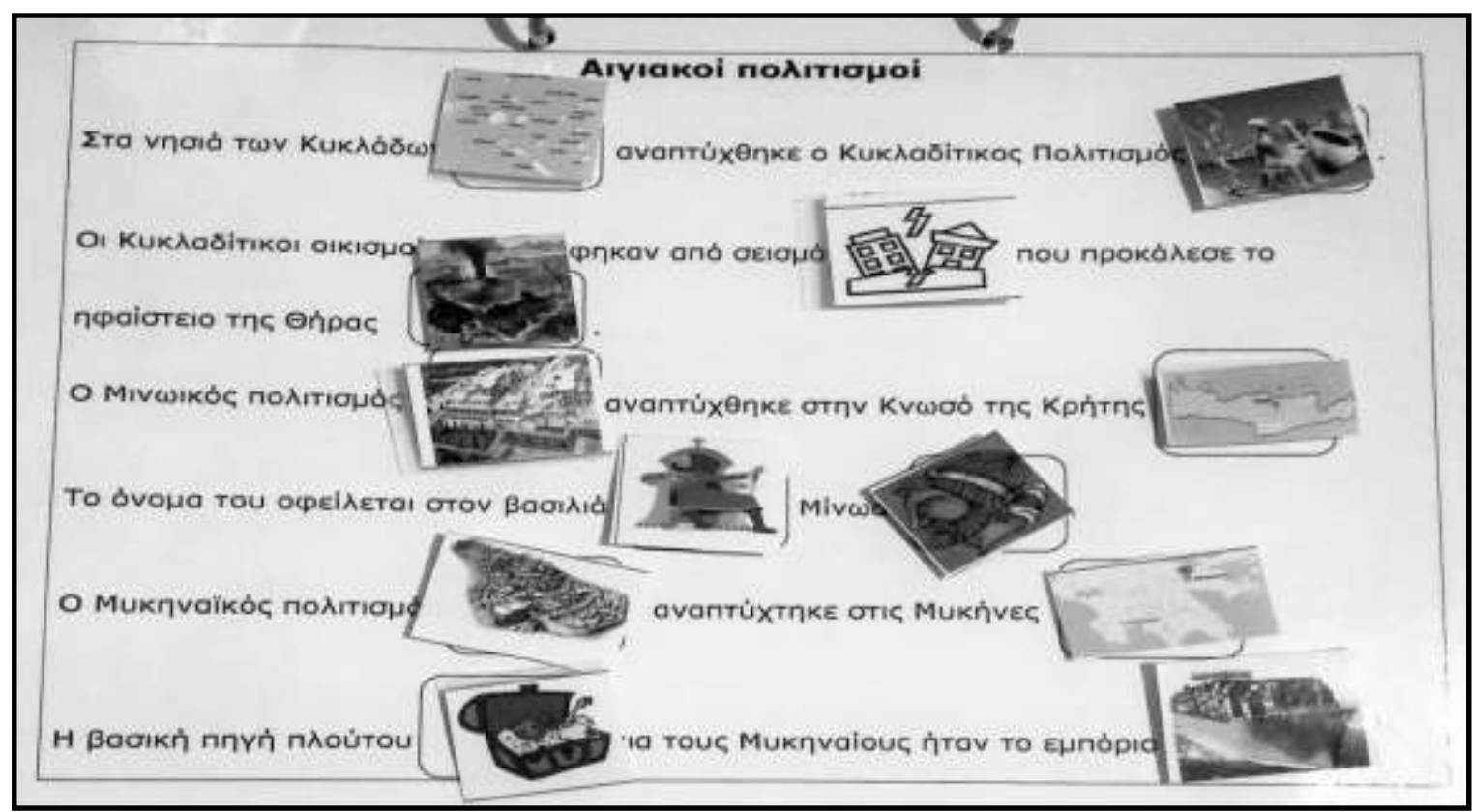

Figure 6. Differentiated text in the lesson "History" with title "The ancient civilization of Aegean Sea" (in greek) 
The student was also improved in oral and written speech skills with the help of differentiated activities that accompanied the differentiated texts and were included in a folder. For example, each time a student read a differentiated text he was required to fill in with cards or visual conceptual facilitators of reasoning (with words like, with words such as livestock, agriculture, fishing, marble figurines, trade, metalwork) so that he could understand deeper meanings of the text and be able to reach reasonable conclusions about historical events or ancient civilizations (figure 7).

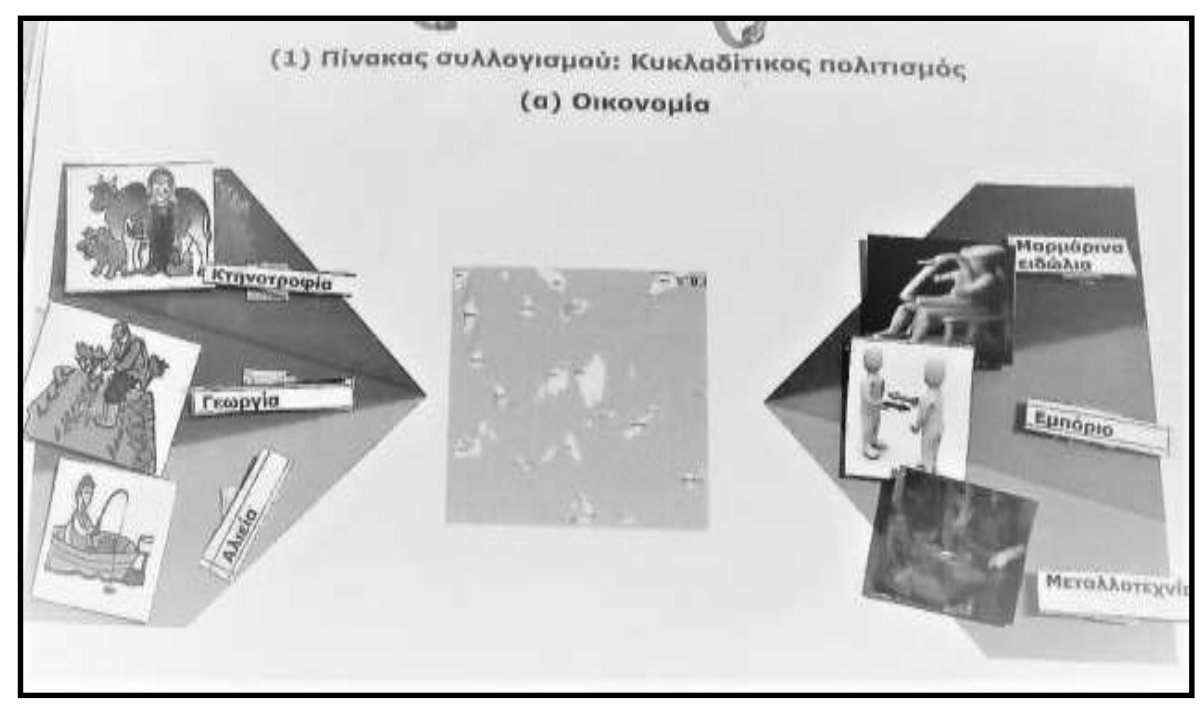

Figure 7. Reasoning table for the Cycladic Civilization (in greek)

He was then asked to design his own reasoning table to make sure he understood the information in the text and, finally, to render the reasoning table verbally or in written form (figure 8).

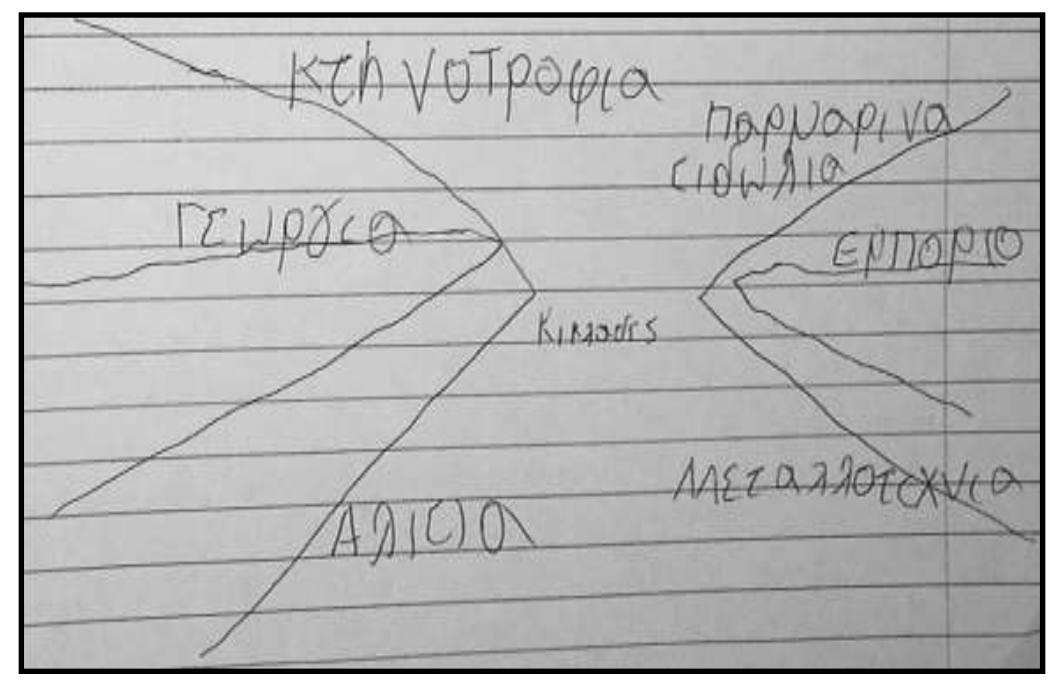

Figure 8. Students with ID draw his own reasoning table (in greek)

\section{Discussion}

The pedagogical tool, TISIPfSENs, supports reading comprehension skills in a mentally disabled student in the secondary school micro-system (Drossinou - Korea, Matousi, Panopoulos, \& 
Paraskevopoulou, 2016). According to Lemons, Allor, Al Otaiba, אal LeJeune (2016), students with intellectual disability are able to cope with reading and comprehension activities through structured curricula based on certain principles, such as: assessing students' needs through informal pedagogical learning assessment, defining realistic teaching goals with teaching steps, implementing scaling-up activities and implementing direct instructions. In the present study, the student with intellectual disability was able to understand the content of the history textbook through differentiated texts and strategies for processing the information provided. According to Fajardo, et al. (2014), in an article he refers to factors that contribute to a better understanding of texts by students with intellectual disabilities such as: (a) the technique of text differentiation (extent, phonological type of words, sentence length, content, use of visual conceptual facilitators), (b) students' reluctance to read lengthy texts and their comprehension strategies, such as discussion, recapitulation, comprehension questions, the use of graphic organizers, where information is schematically represented in tables for being able to better organize and categorize them. It is also found through the present study that the teaching support system for enhancing language skills through the pedagogical tool, TISIPfSENs, is influenced by factors identified in micro-, medium-, external- macro- and time-systems. According to Anderson, Boyle, $\kappa \alpha 1$ Deppeler (2014), inclusive education of students in mainstream schools is accomplished through their participation in the curriculum by achieving teaching goals defined by effective informal pedagogical assessment. However, the same researchers point out that students with SEN in general schools also depend on factors identified in 5 systems formulated through Bronfenbrenner's theory, such as the teacher-pupil relationship, the teaching method, the relationships between people who come into direct contact with the student, the school culture of the teaching staff, the educational system and the educational transitions.

In our research, it was found that the teaching plan to support reading comprehension skills initially depends on the learning profile of the mentally disabled student, which is formulated through informal pedagogical assessment according to some CBSs in order to produce realistic learning objectives (Panopoulos \& Drossinou-Korea, 2019). Based on the case study, it was found that at the microsystem level, and in particular, the binary relationship between teacher of special education and the mentally disabled student, the differentiated material contributed positively to the student's active participation in the syllabus (literacy curriculum) (Drossinou - Korea \& Panopoulos, 2017). At the mesosystem level, it has been observed that special education teacher and collaboration with other adults is an essential prerequisite for effective teaching intervention (Okyere, Aldersey, \& Lysaght, 2019). For example, in the present study the special education teacher worked with the school staff to shape the pupil's school history background and came into contact with her general teacher in order to set a common teaching objective and teaching steps for the History lesson which would be taught. He collaborated with the student's parents to map the family history background and took into account the parents' requests to evaluate and reconcile these requests with the student's real needs. He also had to contact the Diagnostic Center, in order to obtain the student's individual history background and to be informed of the teaching priorities indicated by his therapeutic and teaching staff for a better support to the student's needs. It was also found that, at the exosystem, the teaching of language skills in a student with intellectual disability presupposes the training of special education teachers in inclusive secondary education and the teaching experience in the particular field, which forms the inclusive culture (Gajewski, 2017). In addition, it is concluded with regard to the macrosystem that a form of peer tutoring, such as the institution of parallel support, with the presence of a second teacher in the classroom, advocates enhancing the academic performance of students with intellectual disabilities (Strogilos, Tragoulia, \& Kaila, 2015). At the same level, the general education curriculum and the special education curriculum framework are key parameters for constructing teaching intervention, through which the teacher can structure his or her informal pedagogical assessment and set personalized teaching goals. Finally, with 
regard to chronosystem, we conclude that continuous informal pedagogical assessment (initial, intermediate, and final) during an academic year helps the teacher to have a constant picture of the constantly changing linguistic performance of the learner and the effectiveness of the learner so that he can give feedback on his teaching interventions when needed so that the student with intellectual disability can move on to the next classroom level. (Drossinou-Korea, 2017, pp. 396-398) (Figure 9).

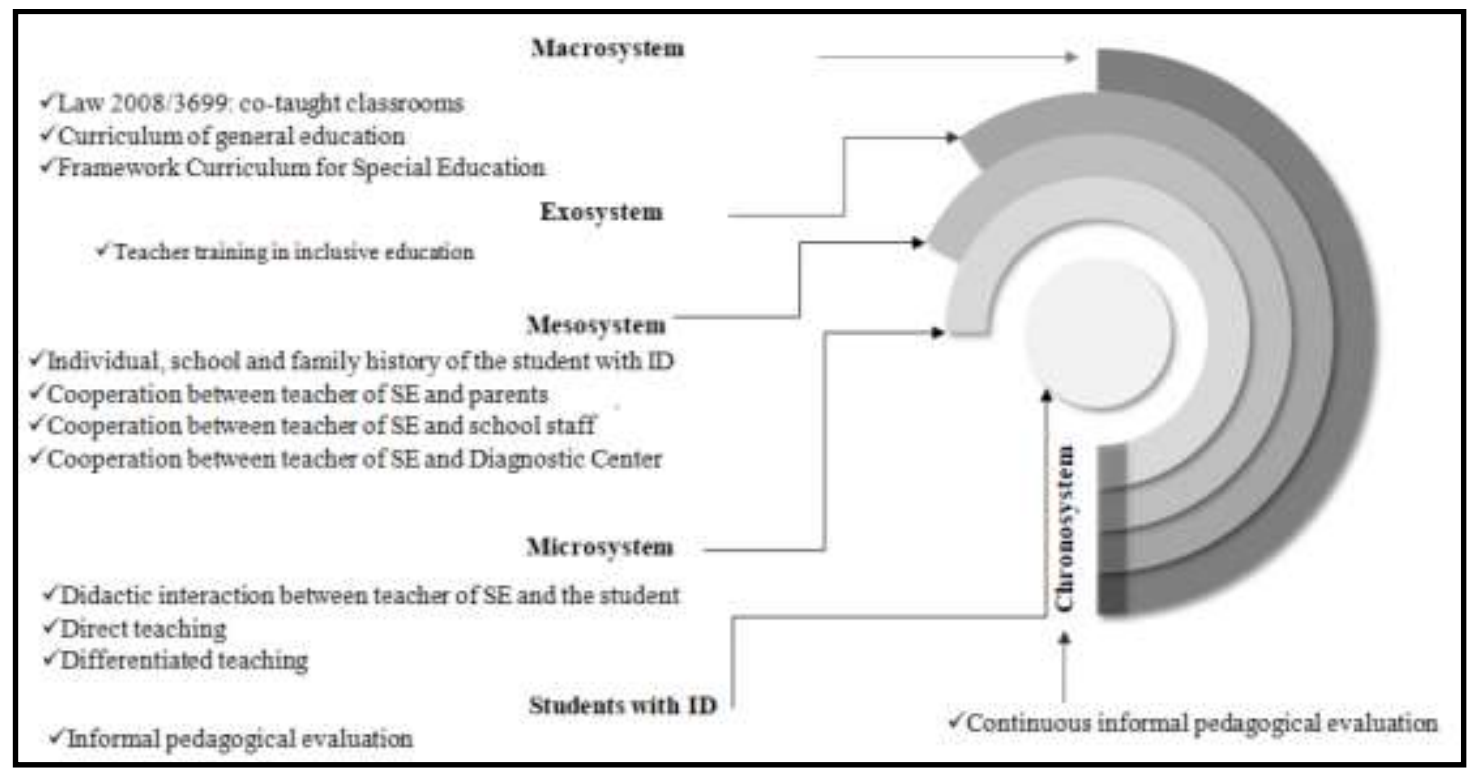

Figure 9. The teaching support of reading skills and the Bronfenbrenner's theory

\section{Conclusions}

Students with intellectual disability can participate in the learning process using TISIPfSENs. This pedagogical tool cultivates their skills, such as comprehension, reading, speech and speaking skills, so that they can participate in the general education curriculum. Furthermore, we believe that the effectiveness of teaching interventions depends on factors such as those defined according to Bronfenbrenner's theory. Therefore, teacher of special education needs to structure his teaching program, taking into account both the principles of TISIPfSENs and the factors of ecological system that directly or indirectly affect the overall development of the student with a intellectual disability.

The present study therefore acts as a trigger for future researchers to examine these parameters in more than four case studies to generalize the conclusions of the present study (Gog, 2015).

\section{Ethics Committee Approval}

The author confirms that ethical approval was obtained from University of Peloponnese Ethics Commission (Approval Date and Number: 09/03/2020- 1471).

\section{Acknowledgements}

I would like to thank the student's parents and the school staff for the permission they gave us to conduct this study. 


\section{References}

Afacan, K., Wilkerson, K., \& Ruppar, A. (2018). Multicomponent reading interventions for students with intellectual disability. Remedial and Special Education, 39(4), 229-242.

Ainscow, M., Dyson, A., \& Weiner, S. (2013). From Exclusion to Inclusion: Ways of Responding inSchools to Students with Special Educational Needs. England: CfBT Education Trust. 60 Queens Road, Reading, RG1 4BS.

Allor, J. H., Mathes, P., Roberts, J., Cheatham, J., \& Champlin, T. (2010). Comprehensive reading instruction for students with intellectual disabilities: Findings from the first three years of a longitudinal study. Psychology in the Schools, 47(5), 445-466.

American Psychiatric Association. (2013). Diagnostic and statistical manual of mental disorders fifth edition (DSM V). Washigton, DC, London, England: American Psychiatric Publishing.

Anderson, J., Boyle, C., \& Deppeler, J. (2014). The ecology of inclusive education. Reconceptualising Bronfenbrenner. In H. Zhang, P. Wing Keung Chan, \& C. Boyle (Eds.), Equality in Education: Fairness and Inclusion (pp. 23-34). Rotterdam: Sense Publishers.

Andrews, G. (2008). Checklists. In L. Given, The SAGE Encyclopedia of qualitative research methods (Vol. 1\&2, pp. 78-79). California: SAGE Publications.

Avramidis, E., \& Kalyva, E. (2006). Research Methods in Special Education. Athens: Papazisi.

Bouck, E. C., \& Bone, E. (2018). Interventions for Students with Intellectual Disabilities. In In Viewpoints on Interventions for Learners with Disabilities (Vol. 33, pp. 55-73). United Kingdom: Emerald Publishing Limited.

Bronfenbrenner, U., \& Morris, P. (2006). The Bioecological Model of Human Development. In R. Lerner (Ed.), Hanbook of chilf psychology. Theoretical Models of Human Development (6 ed., pp. 793-828). Canada: John Wiley \& Sons, Inc.

Channell, M., Loveall, S., \& Conners, F. (2013). Strengths and weaknesses in reading skills of youth with intellectual disabilities. Research in developmental disabilities, 34(2), 776-787.

Dessemontet, R., \& de Chambrier, A. (2015). The role of phonological awareness and letter-sound knowledge in the reading development of children with intellectual disabilities. Research in developmental disabilities, 41-42, 1-12.

Drossinou - Korea, M., \& Panopoulos, N. (2017). Improving reading difficulties in a student with mental retardation: A case study from the Peloponnese Region. Journal of Regional Sociol-Economic Issues, 7(1), 34-48.

Drossinou - Korea, M., Matousi, D., Panopoulos, N., \& Paraskevopoulou, A. (2016). School inclusion programmes (SIPs). Journal of Research in Special Educational Needs, 16(1), 967-971.

Drossinou-Korea, M. (2017). Special education and training. The "through" special education proposal for children with special features. Patra: Opportuna.

Fajardo, I., Ávila, V., Ferrer, A., Tavares, G., Gómez, M., \& Hernández, A. (2014). Easy-to-read texts for students with intellectual disability: linguistic factors affecting comprehension. Journal of Applied Research in Intellectual Disabilities, 27(3), 212-225.

Gajewski, A. (2017). Conceptualizing Professional Ethics in Inclusive Education. In Equity, and Inclusive Education (Vol. 9, pp. 1-21). United Kingdom: Emerald Publishing Limited. 
Gargiulo, R., \& Bouck, E. (2017). Instructional strategies for students with mild, moderate and severe intellectual disability. Los Angeles: Sage Publications, Inc.

Gog, M. (2015). Case study research. International Journal of Sales, Retailing \& Marketing, 4, 33-41.

Hayes, N., O'Toole, L., \& Halpenny, A. (2017). Introducing Bronfenbrenner: A guide for practitioners and students in early years education. New York: Routledge.

Law 3699. (2008). Special education and training for people with disabilities or special educational needs. Government Gazette of the Hellenic Republic No. Sheet 199(1), 3499-3522.

Lemons, C., Allor, J., Al Otaiba, S., \& LeJeune, L. (2016). 0 Research-Based Tips for Enhancing Literacy Instruction for Students With Intellectual Disability. TEACHING Exceptional Children, 49(1), 18-30.

Molfenter, N., \& Hanley-Maxwell, C. (2017). Ethics of inclusion for secondary students with intellectual and developmental disabilities in the United States. In Ethics, Equity, and Inclusive Education (Vol. 9, pp. 79-117). United Kingdom, USA: Emerald Publishing Limited.

Okyere, C., Aldersey, H., \& Lysaght, R. (2019). The experiences of teachers of children with intellectual and developmental disabilities in inclusive schools in Accra, Ghana. Journal of Research in Special Educational Needs, 1-12.

Panopoulos, N., \& Drossinou-Korea, M. (2019). The methodology of observation in a student with intellectual disability. In C. Tsichouridis (Ed.), 4th International Conference on the Promotion of Educational Innovation (pp. 812-821). Larissa: Scientific Association for the Promotion of Educational Innovation.

Petrogiannis, K. (2003). The study of human development-ecosystem approach. Presentation of Urie Bronfenbrenners' theory based on findings from international research. Athens: Kastaniotis.

Rosa, E., \& Tudge, J. (2013). Urie Bronfenbrenner's theory of human development: Its evolution from ecology to bioecology. Journal of Family Theory \& Review, 5(4), 243-258.

Ruppar, A. L., Allcock, H., \& Gonsier-Gerdin, J. (2017). Ecological factors affecting access to general education content and contexts for students with significant disabilities. Remedial and Special Education, 38(1), 53-63.

Schwab, S., Gebhardt, M., Krammer, M., \& Gasteiger-Klicpera, B. (2015). Linking self-rated social inclusion to social behaviour. An empirical study of students with and without special education needs in secondary schools. European Journal of Special Needs Education, 30(1), 1-14.

Strogilos, V., Tragoulia, E., \& Kaila, M. (2015). Curriculum issues and benefits in supportive co-taught classes for students with intellectual disabilities. International Journal of Developmental Disabilities, 61(1), 32-40.

van Wingerden, E., Segers, E., van Balkom, H., \& Verhoeven, L. (2017). Foundations of reading comprehension in children with intellectual disabilities. Research in developmental disabilities, 60, 211-222. 


\section{Bronfenbrenner'in teorisi ve öğretim müdahalesi: Zihinsel engelli öğrenci vakas1}

\section{$\ddot{O} \mathbf{z}$}

Bu çalışmanın amacı Bronfenbrener Ekosistem Teorisi'ne uygun olarak müdahalelerin öğretiminin önemini vurgulamaktır. Araştırma soruları, özel eğitim ihtiyaçları olan öğrenciler (TISIPfSEN) için Hedeflenen, Bireysel, Yapılandırılmış, Entegre Program aracılığıyla okulun mikrosisteminde okuma becerilerinin nasıl öğretildiğini ve ve mezo- ekzo-, makro- ve krono-sistemin okuma becerilerini geliştirmeye yönelik müdahalenin yapısını nasıl şekillendirdiği. ele almaktadır. Metodoloji, Yunanistan'da zihinsel engelli (ID) bir öğrencinin vaka çalışmasını ifade eder. Sonuçlar kimliği olan öğrencinin okuma becerisini geliştirdiğini göstermektedir. Sonuçlar, Bronfenbrener'in Ekosistem Teorisi'ne uygun olarak kimliği olan öğrencilerdeki okuma becerilerinin eğitsel müdahalesini etkileyen ve şekillendiren faktörleri vurgulamaktadır.

Anahtar sözcükler: Zihinsel engelli; okuma becerileri; TISIPfSENs; Bronfenbrenner

\section{AUTHOR BIODATA}

Nikolaos Panopoulos works as a Lecturer of the Speech and Language Therapy Department at University of Peloponnese, Greece.

Maria Drossinou-Korea works as an Assistant Professor of Special Education and Training at Department of Philology, School of Humanities and Cultural Studies at University of Peloponnese, Greece. 